RELATO DE EXPERIÊNCIA

Recebido em: $17 / 10 / 2014$

Aceito em: $01 / 04 / 2015$

\title{
O desafio da formação de auxiliares de biblioteca no Brasil: relato de uma experiência pioneira de educação profissional no sertão paraibano
}

\author{
The challenge of formation of auxiliary library in Brazil: \\ account of a pioneering experience of professional education in \\ paraiba backwoods
}

\author{
Jobson Louis Santos de Almeida \\ Instituto Federal de Educação da Paraíba \\ jobsonlouis@gmail.com \\ Gustavo Henrique de Araújo Freire \\ Universidade Federal da Paraíba \\ ghafreire@gmail.com
}

\section{Resumo}

Relata uma experiência inédita de interiorização da educação profissional no sertão paraibano voltada para o contexto da formação de trabalhadores para bibliotecas, ocorrida no âmbito do Programa de Acesso ao Ensino Técnico e Emprego (PRONATEC) ofertado pelo Instituto Federal da Paraíba - Campus Sousa. Descrevese o perfil e as características particulares do curso Auxiliar de Biblioteca no supracitado contexto social e geográfico. Trata-se de uma pesquisa participante comunicada na forma de relato de experiência. Utilizou-se da pesquisa documental tanto para descrever com rigor e detalhes o perfil do curso analisado, quanto para elucidar as oportunidades de emprego no serviço público para tal segmento. A pesquisa bibliográfica possibilitou a contextualização e fundamentação teórica da abordagem. E a partir dos dados coletados, descritos e analisados foi possível refletir criticamente acerca do potencial dos cursos de formação inicial e continuada para a geração de oportunidades de emprego, transformação cultural e inclusão social. 0 estudo aponta para novos cenários e novas perspectivas de atuação do bibliotecário como agente socialmente responsável por projetos educativos. Concluise que a oferta de cursos de formação de auxiliares de biblioteca em regiões longínquas dos centros urbanos financeiros do país, tal como é o sertão paraibano, além de formar profissionais qualificados para atuarem em bibliotecas, possibilita a disseminação da cultura do livro, da leitura e das bibliotecas, inerente à responsabilidade social da Biblioteconomia e da Ciência da Informação.

Palavras-chave: Educação profissional. Auxiliar de biblioteca. Biblioteca. PRONATEC.

v. 20, n. 42,2015 p. $132-145$

ISSN 1518-2924

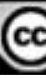

Esta obra está licenciada sob uma Licença Creative Commons. 


\begin{abstract}
Reports an unprecedented experience of internalization of professional education in Paraiba backwoods facing the context of training workers for libraries, which occurred under the Access Program Technical Education and Employment (PRONATEC) offered by the Federal Institute of Paraiba - Campus Sousa. Describes the profile and the particular characteristics of the course Library Assistant in the aforementioned social and geographical context. It is a participant research reported in the form of reporting experience. Was used to describe the documentary research with rigor and detail analyzed the profile of the course. A search led to the contextualization and theoretical basis of the approach. And from the collected data was analyzed and described possible to reflect critically on the potential of the initial and continued to generate employment opportunities, cultural transformation and social inclusion training courses. The study points to new scenarios and new perspectives on the role of the librarian as a socially responsible agent for educational projects. We conclude that the provision of training courses for library assistants in remote areas of financial urban centers of the country, as the Paraiba backwoods, and train skilled professionals to work in libraries, allows dissemination of the culture of the book, the reading and libraries, social responsibility inherent in the Librarianship and Information Science.
\end{abstract}

Keywords: Professional education. Library auxiliary. Library. PRONATEC.

\title{
1 INTRODUÇÃO
}

Aprender, mais que uma escolha, é uma exigência para o mercado de trabalho. Aprende-se ao longo da vida que nunca é tarde para aprender, e que o aprender não é finito. Partindo deste pressuposto, não podemos deixar de refletir sobre a atuação do profissional bibliotecário no atual contexto educacional brasileiro. Destaca-se, na contemporaneidade, como responsabilidade social do profissional da informação (bibliotecário) o papel de facilitar a comunicação do conhecimento para aqueles que dele necessitam na sociedade, contribuindo também para democratizar o uso dos recursos de informação. (FREIRE, 2007; FREIRE, 2004).

Frente às demandas do mercado de trabalho e da sociedade da aprendizagem contínua, surgem, recentemente, políticas educacionais para o universo do trabalho e emprego com o propósito de gerar maior inclusão social no Brasil. Dentre elas, destaca-se a criação do Programa Nacional de Acesso ao Ensino Técnico e Emprego (PRONATEC). Tal Programa foi lançado pela Presidente Dilma Rousseff no ano 2011. Sancionado pela Lei ${ }^{\circ} 12.513$, em 26 de outubro de 2011, o PRONATEC tem como objetivo principal democratizar o acesso da população brasileira à Educação Profissional e Tecnológica (EPT). Este programa está inserido em uma agenda governamental de diversas iniciativas e políticas públicas de expansão da educação profissional promovido pelo Governo Federal nas últimas décadas no cenário brasileiro.

De acordo com a Lei ${ }^{\circ} 12.513 / 2011$, são objetivos do PRONATEC:

I - expandir, interiorizar e democratizar a oferta de cursos de educação profissional técnica de nível médio presencial e à distância e de cursos e programas de formação inicial e continuada ou qualificação profissional;

II - fomentar e apoiar a expansão da rede física de atendimento da educação profissional e tecnológica;

III - contribuir para a melhoria da qualidade do ensino médio público, por meio da articulação com a educação profissional; 
IV - ampliar as oportunidades educacionais dos trabalhadores, por meio do incremento da formação e qualificação profissional;

$\mathrm{V}$ - estimular a difusão de recursos pedagógicos para apoiar a oferta de cursos de educação profissional e tecnológica.

O público-alvo do supracitado programa consiste, prioritariamente, conforme expresso em lei, dos seguintes: estudantes de ensino médio da rede pública (inclusive da educação de jovens e adultos), trabalhadores, beneficiários dos programas federais de transferência de renda e estudantes que tenham cursado o ensino médio completo em escola da rede pública ou em instituições privadas na condição de bolsista integral (BRASIL, 2011).

O PRONATEC caracteriza-se, portanto, como um instrumento de inclusão social, ao fornecer possibilidades de qualificação para um segmento da sociedade caracterizado pela vulnerabilidade socioeconômica. Entenda-se por vulnerabilidade socioeconômica como uma situação de risco para os sujeitos que estão suscetíveis à exclusão econômica e social, pois encontram dificuldades para conseguir uma boa formação profissional devido às baixas condições financeiras de seu contexto familiar.

Nesta conjuntura, está inserido o curso Auxiliar de Biblioteca, objeto de estudo relatado neste artigo. 0 presente artigo consiste em um relato de experiência que descreve o perfil e as características particulares do curso Auxiliar de Biblioteca, ofertado pelo PRONATEC no município de Sousa, localizado no semiárido nordestino. Assim, tem como principal objetivo refletir acerca dos desafios da formação de auxiliares de biblioteca, a partir de uma análise reflexiva do potencial desta prática pioneira no sertão paraibano, destacando-se tanto o potencial da geração de oportunidades de emprego, quanto o de transformação cultural e inclusão social que tal iniciativa representa para a Biblioteconomia e para a sociedade no Estado da Paraíba. Não há relatos anteriores a este sobre tal experiência de formação de Auxiliares de Biblioteca no sertão paraibano registrados na literatura científica dos campos da Educação e da Ciência da Informação, o que justifica a relevância de tal estudo para a literatura científica.

\section{A QUESTÃO DA INTERIORIZAÇÃO DA EDUCAÇÃO PROFISSIONAL A PARTIR DO PRONATEC}

As iniciativas de interiorização da educação profissional nos Estados brasileiros possibilitam desenvolvimento econômico e cultural com inclusão social. Possibilitam, também, geração de oportunidades de emprego para jovens que residem longe dos grandes centros urbanos. O PRONATEC contribui para a formação de cidadãos trabalhadores em seus municípios, em seu território, sem que haja a necessidade de migração para localidades longínquas (por exemplo, centros urbanos) em busca de oportunidades de qualificação profissional. Há, também, o fomento do desenvolvimento regional, que consequentemente, estimula a permanência dos profissionais qualificados no interior do Brasil. Isto se dá pelo engajamento das universidades e institutos federais nas políticas de interiorização da educação profissional do Governo Federal. Tal iniciativa representa um esforço a mais para a redução de iniquidades sociais e desigualdades regionais.

O déficit da educação profissional no Brasil é um problema complexo. E na Lei de Diretrizes e Bases da Educação, a educação profissional é 
apregoada como uma modalidade de ensino que possibilita o acesso ao mercado de trabalho, ou seja, ao emprego. Portanto, o PRONATEC preenche uma lacuna na sociedade brasileira, ofertando cursos de formação e qualificação profissional diversos, em regiões e localidades distintas.

Especificamente, no Estado da Paraíba, o PRONATEC está distribuído por todos os campi do Instituto Federal de Educação da Paraíba (IFPB). Destaca-se que o IFPB está presente em todas as 12 (doze) regiões geoadministrativas do Estado da Paraíba. A interiorização da educação profissional no Estado da Paraíba, pelo PRONATEC, portanto, se dá ampla e significativamente em prol da inclusão social sem distinção geográfica, abrangendo a diversidade cultural e socioeconômica paraibana.

Numa perspectiva histórico-crítica, há que se considerar que o PRONATEC é uma iniciativa recente no Brasil (criado em 2011), e que a ampliação de vagas e ofertas de cursos não necessariamente implica em ganhos qualitativos para a educação profissional no País. Há que se realizar investigações científicas, reflexões coletivas e debates construtivos acerca de tal questão.

No campo da Ciência da Informação, a inclusão e responsabilidade social perpassam os desafios da formação profissional e da geração de oportunidades para o acesso ao emprego.

\section{INCLUSÃO E RESPONSABILIDADE SOCIAL NO CONTEXTO INTERDISCIPLINAR DA CIÊNCIA DA INFORMAÇÃO}

A informação enquanto elemento de inclusão social possibilita a geração de múltiplas oportunidades para as pessoas, tais como: geração de emprego e renda, desenvolvimento de senso crítico, descoberta e possibilidade de construção de novos conhecimentos, e ampliação das perspectivas culturais para leitura e interpretação de mundo. No Brasil a formação de trabalhadores da informação é cada vez mais necessária e demanda esforços conjuntos das organizações privadas, do Governo e da sociedade civil. O PRONATEC é uma iniciativa governamental recente no cenário brasileiro, e representa uma ação de inclusão social de dimensões complexas que faz uso da educação e da informação para transformação social e cultural das pessoas dos grandes centros urbanos às longínquas comunidades rurais.

Neste cenário, a formação de trabalhadores da informação para atuarem em bibliotecas (ou unidades de informação) na conjuntura social em que atua o PRONATEC, relaciona-se diretamente com os fundamentos da responsabilidade social da Ciência da Informação. Afinal, conforme apregoado por Freire (2006, p. 230),

"à medida que se configura a necessidade de socialização da informação para todos, cresce a responsabilidade social da ciência da informaç̧ão, na condição de ciência que tem como função social a organização, processamento e comunicação dessas informações."

Na sociedade do aprendizado contínuo, a informação disponível nas bibliotecas agrega valores intangíveis às políticas públicas de educação e inclusão social. Na contemporaneidade, os esforços empreendidos nos cursos de formação inicial e continuada do PRONATEC destacam-se pela relevância social inclusiva. Bibliotecários passam a atuar como docentes na formação de Auxiliares de Biblioteca, e percebe-se, na prática, a evidência da 
interdisciplinaridade entre Educação e Ciência da Informação em prol do desenvolvimento social, cultural e econômico. Observa-se, também, que a responsabilidade social da Ciência da Informação assume um caráter cada vez mais interdisciplinar e sem fronteiras. A formação de auxiliares de biblioteca no sertão paraibano além de consistir em um desafio da educação profissional, consiste em uma ação concreta de responsabilidade social da Biblioteconomia e da Ciência da Informação através da Educação.

Em uma sociedade complexa e globalizada como a brasileira, os profissionais e os cientistas da informação além de facilitadores da comunicação do conhecimento (FREIRE, 2004), se preocupam com a dimensão social e os impactos dos serviços de informação, conforme apregoado por Serafim e Freire (2012, p.165-166), a partir da concepção de DuMont (1991, p. 203) de que responsabilidade social é um conceito fundamentalmente ético. Nesta perspectiva, consiste em responsabilidade social a participação de Bibliotecários na formação de Auxiliares de Biblioteca, na condição de docentes, em localidades interioranas do Brasil que possuem pouco ou limitado acessos aos serviços de informação de bibliotecas, e pouco incentivo à cultura do livro e da leitura, tal como ocorrem no município de Sousa e adjacências.

0 presente estudo, de cunho interdisciplinar, é a expressão da responsabilidade social no tratamento científico dessa questão no Brasil. E almeja não somente preencher lacunas da literatura científica, mas também contribuir efetivamente para compreensão de um fenômeno social recente e de alta complexidade, despertando o interesse da comunidade científica em Ciência da Informação para questões onde a informação se faz presente, mas que as investigações científicas ainda são escassas.

\section{METODOLOGIA}

Consiste em um relato de experiência descritivo e reflexivo sobre a experiência inédita que consiste a formação de Auxiliares de Biblioteca em um curso de Formação Inicial e Continuada do Programa de Acesso ao Ensino Técnico e Emprego no município de Sousa, Estado da Paraíba. Realizou-se, para tal, pesquisa documental e bibliográfica em website oficial do PRONATEC, diários de classe, relatórios, artigos científicos e livros dos campos da Educação e Ciência da Informação. Optou-se pela realização da pesquisa documental devido a possibilidade que esta técnica oferece para "recolher informações e conhecimentos prévios, acerca de um problema para o qual se procura resposta ou acerca de uma hipótese que se quer experimentar" (CERV0; BERVIAN; SILVA, 2007, p.61). Foi realizada, também, uma pesquisa documental em websites especializados em concursos públicos para identificação dos editais recentes, principalmente na região Nordeste, que ofertaram vagas para o cargo Auxiliar de Biblioteca no ano de 2013. Foram consultados os seguintes portais e websites: PCI Concursos, Jornal dos Concursos, Concursos no Brasil e Folha Dirigida. 0 critério para escolha deste foi o índice de relevância na recuperação da informação no buscador Google quando solicitada uma busca com uso do termo "concursos públicos".

0 universo da pesquisa corresponde ao curso Auxiliar de Biblioteca, ofertado pelo PRONATEC do IFPB, no Centro Vocacional Tecnológico (CVT), iniciado no segundo semestre de 2013 e concluído no primeiro semestre de 2014, no município de Sousa, Estado da Paraíba. 
Um dos membros pesquisadores deste estudo foi professor da turma em três das nove disciplinas ofertadas, e consistiu em um observador participante da formação profissional em questão. Relatos espontâneos dos discentes em sala de aula e dos docentes das demais disciplinas do curso foram relevantes para algumas inferências e reflexões propostas nesse estudo. Propõe-se ao final deste artigo uma reflexão crítica baseada nesta experiência.

\section{RESULTADOS E REFLEXÕES}

O curso Auxiliar de Biblioteca, no âmbito do PRONATEC, é um curso de Formação Inicial e Continuada. Cursos de Formação Inicial Continuada são cursos de qualificação, com duração mínima de 160 horas, que constituem um ponto de partida para a inserção do sujeito aprendente no universo do emprego e do trabalho, ampliando suas perspectivas de carreira.

Apesar da não regulamentação do exercício profissional do Auxiliar de Biblioteca, é perceptível a oferta de empregos tanto no setor privado, quanto no setor público, sendo cada vez mais frequente a presença de vagas para o cargo Auxiliar de Biblioteca nos certames públicos, conforme percebido nos editais recentes, o que justifica a demanda por mão de obra qualificada neste campo profissional, que por si só já se configura como um espaço laboral dinâmico e de frequentes mudanças tecnológicas. Ao analisarmos editais de seleções públicas de emprego para o cargo Auxiliar de Biblioteca, especificamente do ano de 2013, verificaremos que foram realizadas, na região Nordeste do Brasil, 12 (doze) seleções com vagas para tal cargo. E nas demais regiões, 52 (cinquenta e duas) outras seleções, totalizando 64 (sessenta e quatro) oportunidades de emprego em todo o Brasil. As doze seleções ocorridas na região Nordeste, conforme os editais, juntas ofereceram 26 (vinte e seis) vagas para Auxiliar de Biblioteca no ano de 2013. A exigência para que o sujeito ocupe tal cargo é comumente o Ensino Fundamental Completo ou o Ensino Médio Completo, conforme exposto no Quadro 1, que também apresenta informações quanto ao órgão, vencimento, carga horária, quantitativo de vagas e atribuições.

Quadro 1: 0 cargo Auxiliar de Biblioteca nos concursos públicos realizados em 2013 na região Nordeste do Brasil

\begin{tabular}{|c|c|}
\hline $\begin{array}{c}\text { Órgão/Estado } \\
\text { Vencimento } \\
\text { Horária }\end{array}$ & \multicolumn{1}{|c|}{$1.547,23$ (40h) } \\
\hline Requisitos & \multicolumn{1}{|c|}{ Nível Fundamental + Experiência de 12 meses } \\
\hline Vagas & \multicolumn{1}{|c|}{05 (cinco) } \\
\hline & $\begin{array}{l}\text { Atuar no tratamento, recuperação e disseminação da informação e } \\
\text { executar atividades especializadas e administrativas relacionadas à rotina } \\
\text { de unidades ou centros de documentação ou informação, quer no no } \\
\text { atendimento ao usuário, quer na administração do acervo, ou na na } \\
\text { manutenção de bancos de dados. Colaborar no controle e na conservação } \\
\text { de equipamentos. Realizar manutenção do acervo. Participar de } \\
\text { treinamentos e programas de atualização. Auxiliar nas atividades de } \\
\text { ensino, pesquisa e extensão. Utilizar recursos de informática. Executar } \\
\text { outras tarefas de mesma natureza e nível de complexidade associadas ao } \\
\text { ambiente organizacional. }\end{array}$ \\
\hline
\end{tabular}




\begin{tabular}{|c|c|}
\hline Órgão/Estado & $\begin{array}{l}\text { Instituto Federal de Educação de Pernambuco (IFPE) / Estado de } \\
\text { Pernambuco }\end{array}$ \\
\hline $\begin{array}{c}\text { Vencimento } \\
\text { (R\$) e Carga } \\
\text { Horária } \\
\end{array}$ & $1.547,23(40 \mathrm{~h})$ \\
\hline Requisitos & Nível Fundamental + 06 meses de experiência \\
\hline Vagas & 01 (uma) \\
\hline Atribuições & As mesmas atribuições do item anterior (concurso do IFPB). \\
\hline Órgão/Estado & $\begin{array}{l}\text { Universidade Federal do Rio Grande do Norte (UFRN) / Estado do Rio } \\
\text { Grande do Norte }\end{array}$ \\
\hline $\begin{array}{c}\text { Vencimento } \\
\text { (R\$) e Carga } \\
\text { Horária }\end{array}$ & $1.547,23(40 \mathrm{~h})$ \\
\hline Requisitos & Nível Fundamental \\
\hline Vagas & 02 (duas) \\
\hline Atribuições & $\begin{array}{l}\text { Orientar os usuários, com base nos instrumentos normativos, quanto ao } \\
\text { funcionamento da biblioteca e uso do acervo; Atender o usuário quanto } \\
\text { às suas necessidades informacionais; Efetuar empréstimo, renovação e } \\
\text { devolução do material informacional; Executar procedimentos } \\
\text { administrativos relativos ao funcionamento da biblioteca. Localizar, } \\
\text { ordenar e repor itens do acervo bibliográfico nas estantes. Manter em } \\
\text { ordem as dependências da Biblioteca e controlar o uso dos seus espaços; } \\
\text { Solicitar e receber devoluções de empréstimo entre bibliotecas; Receber, } \\
\text { documentar, agradecer e patrimonializar as doações; Manter, organizar e } \\
\text { incrementar o intercâmbio entre bibliotecas; Organizar, atualizar e } \\
\text { manter catálogos de editores; Providenciar a compilação de dados par a } \\
\text { fins estatísticos; Identificar problemas e propor soluções com vistas à } \\
\text { segurança, preservação, conservação, restauração e manutenção do } \\
\text { acervo; Preparar material para encadernação e inspecionar a qualidade } \\
\text { dos itens retornados; Providenciar a execuça de serviços de restauração } \\
\text { simples; Executar preparação final (procedimentos de identificação e } \\
\text { proteção do material informacional); Higienizar os documentos e seus } \\
\text { locais de armazenamento; Auxiliar a execução do inventário do acervo; } \\
\text { Executar serviços de inserção de dados, recuperação de informação e } \\
\text { criação de arquivos em meio eletrônico; Operar aplicativos comuns na } \\
\text { área de Informática; Atuar, em nível básico, nos serviços técnicos de itens } \\
\text { documentais; Realizar procedimentos de organização e expansão do } \\
\text { acervo em seu local de armazenamento; Acompanhar e controlar } \\
\text { vigências de contratos; Organizar, controlar e intercambiar itens } \\
\text { publicados pela Editora Universitária (EDUFRN); Executar outras tarefas } \\
\text { de mesma natureza e nível de complexidade associadas ao ambiente } \\
\text { organizacional. }\end{array}$ \\
\hline Órgão/Estado & Prefeitura de São Gonçalo do Piauí / Estado do Piauí \\
\hline $\begin{array}{c}\text { Vencimento } \\
\text { (R\$) e Carga } \\
\text { Horária }\end{array}$ & $678,00(40 \mathrm{~h})$ \\
\hline Requisitos & Nível Médio \\
\hline Vagas & 01 (uma) \\
\hline Atribuições & Não especificado em Edital. \\
\hline Órgão/Estado & Prefeitura de Livramento de Nossa Senhora / Estado da Bahia \\
\hline $\begin{array}{c}\text { Vencimento } \\
\text { (R\$) e Carga } \\
\text { Horária }\end{array}$ & $678,00(40 h)$ \\
\hline Requisitos & Nível Médio \\
\hline Vagas & $05($ cinco) \\
\hline Atribuições & Atender os leitores, orientando-os no manuseio dos fichários \\
\hline
\end{tabular}




\begin{tabular}{|c|c|}
\hline & $\begin{array}{l}\text { localização de livros e aplicações, para auxiliá-los em suas consultas e } \\
\text { manutenção do Local de trabalho. }\end{array}$ \\
\hline Órgão/Estado & Prefeitura de Cristalândia do Piauí / Estado do Piauí \\
\hline $\begin{array}{l}\text { Vencimento } \\
\text { (R\$) e Carga } \\
\text { Horária }\end{array}$ & $678,00(40 \mathrm{~h})$ \\
\hline Requisitos & Nível Médio \\
\hline Vagas & 01 (uma) \\
\hline Atribuições & Não especificado em Edital. \\
\hline Órgão/Estado & Prefeitura de Tamandaré / Estado de Pernambuco \\
\hline $\begin{array}{l}\text { Vencimento } \\
\text { (R\$) e Carga } \\
\text { Horária }\end{array}$ & $678,00(40 \mathrm{~h})$ \\
\hline Requisitos & Nível Médio \\
\hline Vagas & 02 (duas) \\
\hline Atribuições & $\begin{array}{l}\text { Atender os usuários, orientando-os no manuseio dos fichários e } \\
\text { localização de livros e aplicações, para auxiliá-los em suas consultas; } \\
\text { efetuar o registro dos livros retirados por empréstimos, anotando seus } \\
\text { títulos, autores, códigos de referência, identidade do usuário, data } \\
\text { prevista para a entrega e outros dados de importância, para garantir a } \\
\text { futura devolução dos mesmos e obter dados para levantamento } \\
\text { estatístico; controlar a entrada de livros devolvidos, registrando a data de } \\
\text { devolução dos mesmos e/ou calculando a soma a ser cobrada para as } \\
\text { entregas em atraso, para manter o acervo bibliográfico; repor nas } \\
\text { estantes, os livros utilizados pelos usuários, posicionando-os nas } \\
\text { prateleiras de acordo com o sistema de classificação adotado na } \\
\text { biblioteca, para mantê-los ordenados e possibilitar novas consultas e } \\
\text { registros; manter atualizados os fichários catalográficos de biblioteca, } \\
\text { completando-as e ordenando suas fichas de consulta, para assegurar a } \\
\text { pronta localização dos livros e publicações; }\end{array}$ \\
\hline Órgão & Prefeitura de Itarantim (Estado da Bahia) \\
\hline $\begin{array}{l}\text { Vencimento } \\
\text { (R\$) e Carga } \\
\text { Horária }\end{array}$ & Salário mínimo (40h) \\
\hline Requisitos & Nível Fundamental Completo \\
\hline Vagas & 02 (duas) \\
\hline Atribuições & $\begin{array}{l}\text { Atender os leitores, orientando-os no manuseio dos fichários e } \\
\text { localização de livros e aplicações, para auxiliá-los em suas consultas e } \\
\text { manutenção do Local de trabalho. }\end{array}$ \\
\hline Órgão & Prefeitura de Passa e Fica (Estado do Rio Grande do Norte) \\
\hline $\begin{array}{l}\text { Vencimento } \\
\text { (R\$) e Carga } \\
\text { Horária }\end{array}$ & $678,00(40 \mathrm{~h})$ \\
\hline Requisitos & Nível Médio \\
\hline Vagas & 02 (duas) \\
\hline Atribuições & Não especificado em Edital. \\
\hline Órgão & Prefeitura de Quixaba / Estado de Pernambuco \\
\hline $\begin{array}{l}\text { Vencimento } \\
\text { (R\$) e Carga } \\
\text { Horária }\end{array}$ & $678,00(30 \mathrm{~h})$ \\
\hline Requisitos & Nível Médio \\
\hline Vagas & 03 (três) \\
\hline Atribuições & $\begin{array}{l}\text { Prestar atendimento aos munícipes que fazem uso da biblioteca, } \\
\text { orientando as consultas e pesquisas; Conservar e organizar o acervo da } \\
\text { biblioteca bem como o arquivo dos usuários. Auxiliar na elaboração e }\end{array}$ \\
\hline
\end{tabular}




\begin{tabular}{|c|c|}
\hline & $\begin{array}{l}\text { execução de projetos de incentivo à leitura e colaborar no } \\
\text { desenvolvimento do trabalho no Ambiente de Tecnologia. }\end{array}$ \\
\hline Órgão & Prefeitura de Presidente Médici / Estado do Maranhão \\
\hline $\begin{array}{c}\text { Vencimento } \\
\text { (R\$) e Carga } \\
\text { Horária }\end{array}$ & $678,00(40 \mathrm{~h})$ \\
\hline Requisitos & Nível Médio \\
\hline Vagas & 01 (uma) \\
\hline Atribuições & $\begin{array}{l}\text { Executar atividades na preservação e organização de acervos da } \\
\text { biblioteca municipal e centros de documentação }\end{array}$ \\
\hline Órgão & Prefeitura de Ipecaetá / Estado da Bahia \\
\hline $\begin{array}{c}\text { Vencimento } \\
\text { (R\$) e Carga } \\
\text { Horária }\end{array}$ & $678,00(40 \mathrm{~h})$ \\
\hline Requisitos & Nível Médio \\
\hline Vagas & 01 (uma) \\
\hline Atribuições & $\begin{array}{l}\text { Auxiliar e/ou executar a coleta de registro de dados diversos, } \\
\text { consultando documentos, transcrições, arquivos e fichários; Auxiliar e/ou } \\
\text { executar a manutenção e atualização de fichários e ou arquivos; Auxiliar } \\
\text { no controle de entrega de livros, revistas e similares, providenciando os } \\
\text { formulários de solicitação e registrando a devolução dos mesmos; } \\
\text { Executar serviços de digitação; Atender chamadas telefônicas, anotando e } \\
\text { comunicando as informações; Atender ao público preenchendo fichas, } \\
\text { prestando informações, ou encaminhando o interessado ao setor } \\
\text { competente; Zelar, pela conservação e guardar livros, revistas, jornais, } \\
\text { máquinas, demais materiais e instalações, auxiliando nas vistorias } \\
\text { periódicas; Auxiliar e ou executar tarefas relativas à administração de } \\
\text { pessoal, de material e patrimônio, na preparação de documentos; } \\
\text { Executar outras tarefas afins e correlatas. }\end{array}$ \\
\hline
\end{tabular}

Fonte: Dados da pesquisa documental, 2014.

Observa-se que em alguns processos seletivos há exigência da experiência profissional. Infere-se que isso representa uma tendência para garantir que os candidatos a tal cargo tenham melhor percepção das responsabilidades e atribuições do cargo que ocuparão caso logrem êxito na seleção. Tal cenário, consequentemente, confirma a demanda por iniciativas de educação profissional para a área de Biblioteconomia no que concerne a formação de Auxiliares de Biblioteca.

Também é possível constatar a partir do Quadro 2 que 9 (nove) das 12 (doze) seleções foram para Prefeituras em que a remuneração inicial é de $\mathrm{R} \$$ 678,00 (seiscentos e setenta e oito reais). Enquanto que as outras 3 (três) seleções são para órgãos públicos federais, em que a remuneração inicial é maior: $\mathrm{R} \$ 1.547,23$ (hum mil quinhentos e quarenta e sete reais e vinte e três centavos). Esses dados evidenciam a desigualdade em relação à remuneração entre órgãos públicos no Brasil, que é cenário comum tanto para profissionais Bibliotecários, quanto para Auxiliares de Bibliotecas. Recomenda-se o aperfeiçoamento da legislação para dirimir as disparidades de remuneração entres as esferas municipal, estadual e federal.

A partir das atribuições expostas no Quadro 1 e corroborando com Ferreira (2006), o profissional Auxiliar de Biblioteca é responsável por executar tarefas de apoio ao bibliotecário na aquisição e no processamento técnico, bem como na parte administrativa. Dentre as habilidades demandas 
ao Auxiliar de Biblioteca, na contemporaneidade, destacam-se: comunicação, pensamento lógico, organização, domínio de informática e de tecnologias eletrônicas e digitais.

O curso Auxiliar de Biblioteca, no município de Sousa, no Estado da Paraíba, possuiu em 2013 uma carga horária de 240 horas, e apresentou um conjunto de nove disciplinas, que juntas se propuseram a contribuir com o desenvolvimento de competências e habilidades necessárias à exequibilidade das funções laborais em Bibliotecas. Observa-se coerência entre as atribuições que são exigidas nos certamos públicos conforme observamos no Quadro 1 e as disciplinas ofertadas no curso do PRONATEC em Sousa. Conclui-se, a partir de tais dados, que a carga horária e a ementa das disciplinas são compatíveis às exigências do mercado de trabalho, em que se valoriza a interdisciplinaridade, conforme exibido abaixo, no Quadro 2.

Quadro 2: Ementa e carga horária das disciplinas do curso Auxiliar de Biblioteca no PRONATEC do IFPB Campus Sousa no ano de 2013

\begin{tabular}{|c|c|c|}
\hline DISCIPLINA & EMENTA & $\begin{array}{c}\text { CARGA } \\
\text { HORÁRIA }\end{array}$ \\
\hline $\begin{array}{c}\text { Técnicas de Atendimento ao } \\
\text { Público }\end{array}$ & $\begin{array}{l}\text { Fornece embasamento teórico e prático } \\
\text { sobre as diferentes técnicas de } \\
\text { atendimento ao público em bibliotecas, } \\
\text { incluindo: o serviço de referência; estudo } \\
\text { da excelência e qualidade no atendimento } \\
\text { ao usuário; e noções de organização de } \\
\text { eventos em bibliotecas. }\end{array}$ & $20 \mathrm{~h}$ \\
\hline $\begin{array}{c}\text { Incentivo a leitura e contação } \\
\text { de histórias }\end{array}$ & $\begin{array}{l}\text { Estudo das atividades de incentivo à } \\
\text { prática da leitura e à formação de leitores. } \\
\text { Conhecer as técnicas de contar e recontar } \\
\text { histórias como forma de incentivo à } \\
\text { leitura e formação do leitor a partir da } \\
\text { seleção de textos, confecção de materiais } \\
\text { e dinâmicas diversificadas adequadas ao } \\
\text { público leitor. }\end{array}$ & $20 \mathrm{~h}$ \\
\hline Introdução ao Computador & $\begin{array}{l}\text { Instalação elétrica: conceito básico de } \\
\text { eletricidade; tomadas de ligação; fontes } \\
\text { de alimentação; Evolução histórica do } \\
\text { computador; Introdução à informática: } \\
\text { definição de computadores; medidas da } \\
\text { informática; capacidade de } \\
\text { processamento e armazenamento; Tipos } \\
\text { de computadores; componentes de um } \\
\text { sistema de computação: software e } \\
\text { hardware; Como conectar os periféricos; } \\
\text { Ligar o computador; Instalação e } \\
\text { configuração do sistema operacional } \\
\text { Microsoft Windows 7; Instalação e } \\
\text { configuração de drivers (vídeo, som...) no } \\
\text { sistema operacional Microsoft Windows } \\
\text { 7; Apresentação de alguns aplicativos } \\
\text { básicos do Microsoft Windows 7; } \\
\text { Apresentação de alguns aplicativos } \\
\text { básicos do Microsoft Office 2007/2010, } \\
\text { Word/Excel/PowerPoint; Internet como } \\
\text { uma ferramenta de pesquisa. }\end{array}$ & $20 \mathrm{~h}$ \\
\hline
\end{tabular}




\begin{tabular}{|c|c|c|}
\hline Matemática Aplicada & $\begin{array}{l}\text { Conjuntos numéricos. Funções. Área de } \\
\text { figuras planas. Geometria espacial. } \\
\text { Matrizes, determinantes e sistemas } \\
\text { lineares. Geometria analítica. Noções de } \\
\text { limites e derivadas. }\end{array}$ & $20 \mathrm{~h}$ \\
\hline Gestão da Biblioteca Escolar & $\begin{array}{l}\text { Noções de gestão da biblioteca escolar. } \\
\text { Estudo da importância da biblioteca } \\
\text { escolar no contexto educacional. }\end{array}$ & $40 \mathrm{~h}$ \\
\hline $\begin{array}{c}\text { Organização e Administração } \\
\text { de Bibliotecas }\end{array}$ & $\begin{array}{l}\text { Estudo dos fundamentos de organização, } \\
\text { funcionamento e administração de } \\
\text { Bibliotecas. Aplicação dos princípios, das } \\
\text { teorias e técnicas da administração em } \\
\text { serviços de informação. }\end{array}$ & $20 \mathrm{~h}$ \\
\hline $\begin{array}{l}\text { Organização e tratamento do } \\
\text { acervo }\end{array}$ & $\begin{array}{l}\text { Descreve as técnicas mais usuais para } \\
\text { organização e tratamento do acervo em } \\
\text { bibliotecas, incluindo o estudo das formas } \\
\text { de representação da informação e } \\
\text { orientação quanto ao uso e a importância } \\
\text { dos sistemas de automação em } \\
\text { bibliotecas. }\end{array}$ & $40 \mathrm{~h}$ \\
\hline $\begin{array}{c}\text { Preservação e conservação de } \\
\text { acervos }\end{array}$ & $\begin{array}{l}\text { Descreve técnicas de preservação e } \\
\text { conservação de acervos de bibliotecas. } \\
\text { Estudo das principais características que } \\
\text { devem estar presentes em um } \\
\text { planejamento voltado para a preservação } \\
\text { e conservação dos acervos bibliográficos. }\end{array}$ & $40 \mathrm{~h}$ \\
\hline Comunicação e Leitura & $\begin{array}{l}\text { Essa disciplina visa o aprimoramento da } \\
\text { expressão oral, a compreensão e } \\
\text { produção de textos correlatos ao Curso de } \\
\text { Auxiliar de Biblioteca. Tópicos de } \\
\text { Gramática aplicada aos textos (coesão e } \\
\text { coerência linguística; organicidade; } \\
\text { estruturação de parágrafos, concordância, } \\
\text { ortografia acentuação, regência verbo- } \\
\text { nominal, pontuação), análise e interação } \\
\text { verbal em diferentes situações de } \\
\text { produção. }\end{array}$ & $20 \mathrm{~h}$ \\
\hline TOTAL & $240 \mathrm{~h}$ & \\
\hline
\end{tabular}

Fonte: Dados da pesquisa documental, 2014.

Dos 30 (trinta) matriculados na turma pioneira do curso Auxiliar de Biblioteca, do PRONATEC no município de Sousa, 19 (dezenove) aprendentes concluíram a formação profissional. 11 (onze) desses aprendentes desistiram por motivos diversos não identificados. Uma das dificuldades na realização do presente estudo é que não possível identificar os reais motivos da evasão de cada sujeito. Entretanto, tal evasão não prejudicou o funcionamento da turma, pois o critério mínimo para funcionamento das turmas no PRONATEC é possuir 16 (dezesseis) alunos, que corresponde a 50\% mais um do número de vagas ofertadas.

Com a Lei no 12.244/2010, as oportunidades para Bibliotecários e, consequentemente, para Auxiliares de Biblioteca, deverão ser exponencialmente crescentes para além de 2020, ano que encerra o prazo para as instituições de ensino de todo o País regularizarem sua situação e possuírem ao menos uma biblioteca em suas dependências, respeitando-se o exercício profissional do Bibliotecário, conforme expresso em lei específica. 
Este é um tema de grande destaque no contemporâneo contexto da Biblioteconomia Brasileira.

Constatou-se que outros cursos de formação profissional de Auxiliares de Biblioteca foram desenvolvidos paralelamente a este em outras mesorregiões do Estado da Paraíba. Entretanto, no sertão paraibano, apenas o município de Sousa ofertou tal curso pelo PRONATEC, pioneiramente, no ano de 2013. Em 2014, no município de Sousa, foram ofertadas 60 (sessenta) vagas para o curso Auxiliar de Biblioteca, sendo as vagas divididas em duas turmas, com aproximadamente 30 (trinta) aprendentes cada. Em 2014 a disciplina "Matemática" foi retirada da matriz curricular. Observou-se que foram reduzidas as cargas horárias das seguintes disciplinas: "Preservação e Conservação de Acervos" que passou a ser de 34 horas (decréscimo de 6 horas), "Gestão da Biblioteca Escolar" com 30 horas (decréscimo de 10 horas), e "Introdução ao Computador" com 16 horas (decréscimo de 4 horas). No total, o curso que antes possuía uma carga horária total de 240 horas, passou a ser realizado em 200 horas, verificando-se um decréscimo de 40 horas na formação. Não há ainda evidências ou relatos que indiquem que tal redução de carga horária seja prejudicial para a formação profissional. As causas de tais alterações curriculares não foram identificadas.

Infere-se que quanto mais qualificados são os auxiliares de bibliotecas, mais eles poderão ir além do trabalho de rotina, colaborando com o(s) bibliotecário(s) em atividades de planejamento, gestão e avaliação de produtos e serviços de informação. Observa-se, por meio dos relatos espontâneos proferidos pelos discentes em sala de aula, que à medida que mais pessoas se conscientizam de como funcionam as bibliotecas e qual o papel do bibliotecário e dos auxiliares de bibliotecas, maior importância e respeito tendem a ter pela cultura do livro, da leitura e das bibliotecas. Esse dado foi obtido por meio da vivência com os discentes do curso e conversas informais com outros docentes do mesmo curso.

Foram identificadas apenas 4 (quatro) bibliotecas com bibliotecários no município de Sousa. Entretanto, esse quantitativo é expressivo para uma localidade com aproximadamente 70 mil habitantes. As instituições que possuem bibliotecas com bibliotecários são: o Centro Cultural do Banco do Nordeste, a Universidade Federal de Campina Grande, o Instituto Federal de Educação da Paraíba, e a Prefeitura Municipal de Sousa.

\section{CONSIDERAÇÕES FINAIS}

0 ineditismo da formação profissional de Auxiliares de Biblioteca numa região que demanda por políticas e iniciativas de inclusão e desenvolvimento social, conforme é o sertão paraibano, já consiste em uma ação empreendedora e significativa. 0 foco na educação profissional voltada para o trabalho com a informação evidencia a práxis das relações interdisciplinares entre Educação e Ciência da Informação na contemporaneidade.

A oferta do curso "Auxiliar de Biblioteca" pelo PRONATEC, possibilita para o município de Sousa e adjacências, a formação de profissionais aptos a trabalharem em bibliotecas. Trata-se do início de uma transformação social e cultural. Tal iniciativa representa o começo de ações coerentes com o texto da lei no 12.244 , de 24 de maio de 2010, que dispõe sobre a universalização das bibliotecas nas instituições de ensino do Brasil. Na supracitada lei, está expresso que os sistemas de ensino do país deverão desenvolver esforços 
progressivos para que haja a universalização das bibliotecas escolares, desde que respeitada a profissão de Bibliotecário. Com isto, podemos afirmar que mais iniciativas de formação de Auxiliares de Biblioteca precisam ser empreendidas por todo o Estado da Paraíba, tendo em vista a viabilidade e importância das mesmas. Conforme apregoado por Silva e Araújo (2014) "bibliotecários sem auxiliares capacitados são como médicos sem enfermeiros". Fica evidente que Auxiliares de Biblioteca não substituem Bibliotecários (com formação superior em Biblioteconomia). Na complexidade dos serviços em informação, ambos os profissionais complementam-se na sociedade do aprendizado contínuo.

No segundo semestre de 2014, duas turmas serão formadas no curso Auxiliar de Biblioteca pelo PRONATEC no município de Sousa, representando os esforços progressivos do Governo Federal e dos profissionais da educação para qualificação de tais profissionais. Isto contribui não somente para a formação de novos e mais qualificados profissionais, mas também para possibilitar que a cultura do livro, da leitura e das bibliotecas seja disseminada por regiões de precário desenvolvimento socioeconômico. Desta forma a inclusão social ocorre, também, pelo desenvolvimento de iniciativas de educação profissional. Recomenda-se que estudos e investigações científicas sejam continuamente elaborados e executados para acompanhar o desenvolvimento destas práticas de formação profissional, principalmente nas regiões interioranas dos Estados brasileiros, que em sua maioria não dispõem sequer de cursos superiores de Biblioteconomia.

\section{REFERÊNCIAS}

BRASIL. Lei no 12.244, de 24 de maio de 2010. Dispõe sobre a universalização das bibliotecas nas instituições de ensino do País. Disponível em: http://www.planalto.gov.br/ccivil_03/_Ato2007-

2010/2010/Lei/L12244.htm. Acesso em 04/05/2014.

BRASIL. Ministério de Educação e Cultura. LDB - Lei no 9394/96, de 20 de dezembro de 1996. Estabelece as diretrizes e bases da Educação Nacional. Brasília/DF: MEC, 1996.

BRASIL. Ministério da Educação. Lei no 12.513, de 26 de outubro de 2011. Institui o Programa Nacional de Ensino Técnico e Emprego (PRONATEC). Brasília/DF: MEC, 2011.

BRASIL. Projeto político-pedagógico do curso auxiliar de biblioteca. Sousa: PRONATEC, 2013.

CASSIOLATO, M. M. M. C.; GARCIA, R. C. PRONATEC: múltiplos arranjos e ações para ampliar o acesso à educação profissional. Rio de Janeiro: IPEA, 2014.

CERVO, A. L.; BERVIAN, P. A.; SILVA, R. Metodologia científica. 6. ed. São Paulo: Pearson Prentice Hall, 2007.

DU MONT, R. R. Ethics in librarianship: a management model. Library Trends, v. 40, n. 2, p. 201-15, 1991. 
FERREIRA, R. da S. Auxiliares de biblioteca e trabalho informacional: desafios e possibilidades para o Sibi/UFPA. Ciência da Informação, v. 35, n. 1, p. 102114, jan./abr. 2006. Disponível em:

http://www.scielo.br/pdf/ci/v35n1/v35n1a11.pdf. Acesso em 17/02/2014.

FREIRE, G. H. de A. O trabalho de informação na sociedade do aprendizado contínuo. Informação \& Sociedade: Estudos, v. 17, n. 3, p. 39-45, set./dez. 2007.

FREIRE, I. M. 0 desafio da inclusão digital. Transinformação, v. 16, n. 2, p. 189-194, maio/ago. 2004.

. Janelas da cultura local: abrindo oportunidades para inclusão digital de comunidades. Ciência da Informação, v. 35, n. 3, p. 227-235, set./dez. 2006.

QUEIROZ, A. A. et al. (orgs.). Capacitação tecnológica da população. Brasília/DF: Câmara dos Deputados/Coordenação de Publicações, 2007.

SERAFIM, L. A.; FREIRE, G. H. de A. Ações de responsabilidade social para competências em informação. Perspectivas em Ciência da Informação, v. 17, n. 3, p. 155-173, jul./set. 2012.

SILVA, D. A. da; ARAUJO, I. Auxiliar de biblioteca: técnicas e práticas para formação profissional. 7 ed. Brasília/DF: Thesaurus, 2014. 